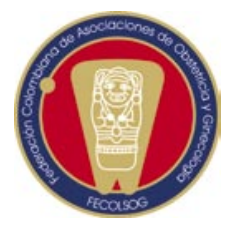

\title{
EDITORIAL
}

\section{SITUACIÓN ACTUAL DE LA REVISTA COLOMBIANA DE OBSTETRICIA Y GINECOLOGÍA}

\author{
José William León, M.D.*
}

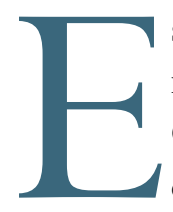

s altamente gratificante presentar este número de la Revista Colombiana de Obstetricia y Ginecología, que es patrocinada por la Federación Colombiana de Asociaciones de Obstetricia y Ginecología (antigua Sociedad Colombiana de Obstetricia y Ginecología), en el momento que ésta atraviesa por su mejor momento desde el punto de vista académico y por ser evidente que ha respondido a las expectativas de los autores, de los lectores, de los asociados y del personal científico nacional e internacional, que la han adoptado como texto de imprescindible consulta.

Es de destacar que por su calidad científica ha aplicado y calificado para su publicación, en la base electrónica de datos SciELO (Scientific Electronic Library Online), orientada a proveer acceso en texto completo, como parte integral del proyecto FAPESP - BIREME, donde ya se encuentran disponibles 28 números texto completo. Adicionalmente, constituye un propósito ineludible en el presente año aplicar a la base de datos MEDLINE lo que permitirá aumentar su visibilidad internacional con las consecuentes ventajas para la difusión de la investigación local y por ende de sus autores.

Como revista científica tiene una existencia certificada según las normas internacionales por el International Standard Serial Number (ISSN), ostenta una estructura administrativa definida y pública, posee una periodicidad declarada y respetada que transciende los límites institucionales y nacionales

* Presidente Federación Colombiana de Asociaciones de Obstetricia y Ginecología (FECOLSOG) y está abierta a las comunidades de especialistas de todo el mundo, cuyos miembros someten sus propuestas de artículos para ser publicados. Por tal razón, la revista aparece indexada por Colciencias en la categoría “C” y actualmente reúne los requisitos para ser reclasificada en la categoría "B". Es de advertir, que según el reporte de Colciencias para el año 2004 y hasta marzo del 2005, solamente diez revistas colombianas han superado el proceso de indexación en las bases de datos mencionadas, lo que resalta la calidad y trascendencia de nuestra publicación.

No obstante, frente al panorama de éxito vislumbrado, no podemos ocultar que así como la calidad de la revista se optimiza de manera permanente, también los costos se incrementan día a día, como consecuencia del proceso de modernización en su presentación y las erogaciones que obviamente se generan para retribuir la dedicación y esfuerzo del personal de edición y traducción, al igual que la subvención de otros gastos inherentes a su impresión y distribución.

Como es de conocimiento de los asociados, nuestras ediciones no están subvencionadas y en la reforma de estatutos del día once (11) de abril de 2003, se propuso que los miembros de la sociedad "fueran merecedores de la revista" por lo que a partir de ese instante su distribución es de carácter gratuita. Pese que se han realizado ingentes esfuerzos para conseguir un sólido financiamiento, la pauta publicitaria no es suficiente para cubrir los costos de la revista, presentándose a la fecha un déficit superior a los ciento veintitrés millones de pesos 
(\$123’000.000). Es de resaltar que los laboratorios farmacéuticos y otros grupos que distribuyen elementos relacionados con la ginecoobstetricia, por razones económicas que no escapan a la realidad del país, han restringido sus pautas publicitarias lo que contribuye de manera definitiva a la problemática económica descrita.

Constituye un compromiso ineludible continuar con nuestros objetivos científicos en la medida en que, a diferencia de las editoriales privadas, somos una entidad netamente académica, cuyo propósito esencial es difundir el conocimiento ligado a la ginecología y obstetricia. Esta noble misión nos compete a todos los asociados mediante el esfuerzo mancomunado, contribuyendo a mejorar la acreditación y reclasificación de indexación de la revista, mediante publicaciones de alta calidad científica y participando en la misma mediante sugerencias y apoyo constructivo.

Es labor titánica sostener económicamente una revista científica a largo plazo, máxime cuando su distribución es gratuita; por ello, condicionado por las cifras económicas anteriormente reseñadas, expongo a ustedes la necesidad de reconsiderar la decisión adoptada en la reforma estatutaria, para como acto solidario, racional y creativo, aceptar que de manera conciliada se establezca una tarifa de cobro racional para los asociados, que permita que la publicación sea autosostenible manteniendo su excelente nivel científico.

La Federación tienen como objetivo primordial propender por la educación médica continua a sus afiliados, misión que se hace viable mediante la realización y patrocinio de congresos y la publicación de la revista. Sin embargo, de continuar la situación expuesta, todas las actividades que se desarrollen para fortalecer económicamente la Federación se verían necesariamente dirigidas con exclusividad al financiamiento de la revista, lo que limitaría los objetivos propuestos, en desmedro de todos sus miembros.

Por último, considero que pagar por la suscripción de la revista constituye una inversión, no sólo por su calidad científica como beneficio inmediato, sino porque permitirá que la Federación amplíe sus horizontes en beneficio de todos sus asociados. Es necesario tener permanentes ideales y metas, tal como lo dijo Napoleon Hill: "Acaricie sus visiones y sus sueños porque son hijos de su alma, el boceto de sus logros finales". 